Original article

\title{
Ultrasound diagnosis of congestion in the pulmonary and systemic circulations in patients with atrial fibrillation and chronic heart failure
}

\author{
Venera V. Kirillova ${ }^{1,2}$, Andrey V. Smorgon ${ }^{3}$, Alla A. Garganeeva ${ }^{3}$, Roman E. Batalov ${ }^{3}$, Viktor N. Meshchaninov ${ }^{1,2}$, \\ Lyudmila A. Sokolova ${ }^{1}$, Maria S. Blagodareva ${ }^{1,2}$, Mikhail S. Khlynin ${ }^{3}$, Sergey V. Popov ${ }^{3}$ \\ 1 Ural State Medical University, Ekaterinburg, Russia \\ 2 Institute for Medical Cell Technology, Ekaterinburg, Russia \\ ${ }^{3}$ Tomsk National Medical Research Center, Tomsk, Russia
}

Received 30 April 2021, Revised 27 July 2021, Accepted 15 November 2021

C 2021, Russian Open Medical Journal

\begin{abstract}
Rationale - Fluid retention is among the most common causes of heart failure decompensation. The goal of our study was to evaluate the sensitivity and specificity of the ultrasound method for evaluating congestive phenomena in both systemic and pulmonary circulatory systems in patients with atrial fibrillation (AF) and chronic heart failure (CHF).

Material and Methods - The study included 28 patients with paroxysmal AF, with or without CHF, who were scheduled for radiofrequency pulmonary vein isolation. The maximum and minimum diameters of the right superior pulmonary vein (RSPV) and inferior vena cava (IVC) were measured via echocardiography on expiration. Mean blood pressure in both right and left atria was measured intraoperatively. We calculated the correlations between maximum and minimum diameters of the RSPV and a mean pressure in the left atrium, as well as between IVC on expiration and a mean pressure in the right atrium, and evaluated the sensitivity and specificity of ultrasound diagnostics for evaluating congestive phenomena in both systemic and pulmonary circulation.

Results - We established positive correlation between the minimum diameter of RSPV and invasively measured mean left atrial pressure $(R=0.65, P<0.05)$, and between invasively measured mean right atrial pressure and IVC diameter on expiration $(R=0.49, P<0.05)$. The proposed method sensitivity for detecting pulmonary venous hypertension (PVH) on the basis of the maximum RSPV diameter $\geq 21.7 \mathrm{~mm}$ was $75 \%$, and the specificity was $86 \%$. The sensitivity and specificity for detecting PVH on the basis of the minimum RSPV diameter $\geq 10.5$ $\mathrm{mm}$ constituted $85 \%$ and $86 \%$, respectively. When using the IVC diameter on expiration $\geq 18.5 \mathrm{~mm}$ as an indicator, the sensitivity and specificity for detecting PVH were evaluated at the levels of $100 \%$ and $92 \%$, correspondingly.

Conclusion - The proposed ultrasound method of diagnosing congestion in pulmonary circulation via maximum and/or minimum diameter of the RSPV can be effectively employed in clinical practice in the same way as conventional technique of congestion diagnostics in systemic circulation via the diameter of IVC in patients with atrial fibrillation and chronic heart failure.
\end{abstract}

Keywords: hyperemia, pulmonary circulation, systemic circulation, diameter of the right superior pulmonary vein, diameter of the inferior vena cava, atrial fibrillation, chronic heart failure.

Cite as Kirillova VV, Smorgon AV, Garganeeva AA, Batalov RE, Meshchaninov VN, Sokolova LA, Blagodareva MS, Khlynin MS, Sergey V. Popov SV. Ultrasound diagnosis of congestion in the pulmonary and systemic circulations in patients with atrial fibrillation and chronic heart failure. Russian Open Medical Journal 2021; 10: e0415.

Correspondence to Venera V. Kirillova. Address: Department of Biochemistry, Ural State Medical University, 3 Repina St., Ekaterinburg 620028, Russia. Phone: +7912270 8496. E-mail: venova@list.ru.

\section{Introduction}

Heart failure is among the major causes of hospital admission with a high risk of readmission [1]. According to randomized studies, the risk of atrial fibrillation (AF) increases with a functional class (FC) of chronic heart failure (CHF) [2]. In large European registries, the prevalence of $\mathrm{AF}$ among patients, hospitalized for CHF ranged from $35-42 \%[3,4]$. Simultaneous presence of AF and CHF not only deteriorates the patient's quality of life, but also increases the hospitalization rate and mortality [5].

Most patients with heart failure (76\%), admitted for inpatient treatment, are 'wet' and 'warm' - i.e., they represent the congestive type with a normal peripheral perfusion [6]. However, only $44 \%$ of patients complain of dyspnea at rest [7]. Therefore, it is important to perform instrumental diagnostics of fluid retention in patients with CHF as early as possible in order to prevent the decompensation, represented by progressive fluid accumulation in the body. When underestimated by clinicians, the severity of CHF may result in unsuitable treatment, including refusal from loop diuretics or prescribing wrong doses [8], and, consequently, the number of wet patients increases.

According to the recommendations for CHF diagnostics and treatment, congestion in systemic and pulmonary circulatory systems is diagnosed symptomatically; however, the symptoms exhibit either low specificity or low sensitivity, thereby allowing to diagnose venous congestion only at its later stages $[9,10]$. Among 
instrumental diagnostic methods, chest radiography is capable of detecting the lung congestion and pleural fluid, but $20 \%$ of patients with congestion have a normal chest X-ray [11]. Compared with the chest $\mathrm{X}$-ray, the number of $\mathrm{B}$-lines on lung ultrasonography more effectively excludes the interstitial edema and pleural effusion. However, the disadvantage of this technique is represented by late diagnostics of congestion in the pulmonary circulation (i.e., at the stage of interstitial edema). Besides, the method does not allow differentiating among the causes of interstitial and alveolar pulmonary edema [11]. Determined via echocardiography, the ratio of the maximum filling velocity in the left ventricle (LV) during early diastole to the maximum velocity of movement of the mitral valve annulus in early diastole phase, $\mathrm{E} / \mathrm{e}^{\prime}$ $\geq 15$, correlates with an increased filling pressure of the LV, whereas $E / e^{\prime}<8$ is indicative of the normal value of the latter. However, at values of $E / e^{\prime}$ ranging $8-15$, a wide range of early diastolic pressure values in the LV is detected, which requires additional diagnostics for this group of patients [12]. The sensitivity of $E / e^{\prime}>12$ is $66 \%$, while its specificity is $55 \%$ [11].

In the presence of right ventricular (RV) insufficiency, there is an increase in end-diastolic pressure in RV and pressure in the right atrium (RA), as well as a difficulty in blood flow towards the heart. As a result, the inferior vena cava (IVC) expands and its collapse during inspiration decreases. The expanded IVC without signs of collapse indicates a significant pressure increase in RA of over $15 \mathrm{~mm} \mathrm{Hg}$ [13]. The sensitivity of the 'IVC collapse less than 50\%' symptom as an indicator of RA pressure increase is $12 \%$, and its specificity is $27 \%$. The sensitivity of the IVC diameter during inspiration below $12 \mathrm{~mm}^{\prime}$ indicator of RA pressure increase is $67 \%$, and its specificity is $91 \%$ [11].

Cardiac catheterization with a direct pressure measurement in the atria and pulmonary artery with the estimate of pulmonary capillary wedge pressure (PCWP) is the gold standard of diagnosing the congestive phenomena in CHF. However, the invasiveness of this technique significantly limits its applicability in clinical practice. Hence, available and easily reproducible instrumental methods, allowing to diagnose the congestive phenomena in pulmonary and systemic circulatory systems even at early CHF stages, are in dire need. They are essential for the proper treatment, including diuretic therapy, in order to prevent CHF decompensation.

The goal of our study was to estimate the sensitivity and specificity of the newly proposed ultrasound method for diagnosing the pulmonary venous hypertension (PVH) by the maximum and minimum diameters of the right superior pulmonary vein (RSPV) in the same way as the conventional technique for congestive phenomena detection in systemic circulation by IVC diameter on expiration in patients with paroxysmal $\mathrm{AF}$, and with or without CHF.

\section{Material and Methods}

\section{Patients}

We prospectively recruited 64 adult subjects who were examined for paroxysmal AF at the Department of Cardiology, Cardiology Research Institute of Tomsk, Russia, from March through May of 2019. The presence of cardiovascular diseases (coronary artery disease, essential hypertension), paroxysmal $\mathrm{AF}$ were the inclusion criteria. All patients with or without CHF were scheduled for radiofrequency pulmonary vein isolation (PVI). CHF was diagnosed sensu the latest recommendations on $\mathrm{CHF}$ diagnostics $[9,10]$. Subjects without established CHF were asymptomatic patients with paroxysmal AF. The exclusion criteria encompassed the acute coronary syndrome, pulmonary embolism, congenital and acquired heart valve diseases, thyroid diseases, menopausal disorders, acute and chronic kidney diseases, acute and chronic pulmonary diseases, and cancer of all types. The total of 28 patients with paroxysmal AF were distributed among two groups, depending on the presence or absence of CHF in the anamnesis. Group 1 included 19 patients, $61.72 \pm 3.66$ years of age, with CHF of FC I-III sensu the classification by New York Heart Association (NYHA). Group 2 comprised 9 patients $55.83 \pm 6.62$ years old without CHF. The control group consisted of 44 virtually healthy individuals $35.02 \pm 2.44$ years old who were previously examined at Uralskaya Clinic LLC (Ekaterinburg, Russia).

An informed consent to participate in the study was obtained from all participants. The study was approved by the local Ethics Committee at the Research Institute of Cardiology, Tomsk, Russia.

\section{Echocardiographic study}

Transthoracic echocardiography in the sinus rhythm was performed in all patients with the Philips HD-15 device (USA), according to the standard protocol. Additionally, the maximum and minimum diameters of RSPV were determined from the suboccipital view. The maximum diameter of RSPV was measured in the ventricular systole phase; the minimum diameter was measured in the atrial systole phase [14, 15].

Besides, mean wedge pressure in the pulmonary artery (PAWP) was calculated by the following formula [16]: mean $P A W P=1.24 \mathrm{E} / \mathrm{e}^{\prime}+1.9$ (where $\mathrm{E}$ is the peak velocity blood flow from LV relaxation in early diastole, based the data by Doppler sonography of the transmitral flow; and $e^{\prime}$ is the peak velocity blood flow of the early diastolic movement of the mitral valve lateral segment, based on the data of the pulse-wave tissue Doppler.

Also, mean right atrial pressure (RAP) was calculated by the following formula [17]: mean $\mathrm{RAP}=1.7 \mathrm{E} / \mathrm{e}^{\prime}+0.8$, where $\mathrm{E}$ is the peak velocity blood flow from RV relaxation in early diastole, based the data by Doppler sonography of the diastolic flow through the tricuspid valve; and $\mathrm{e}^{\prime}$ is the peak velocity blood flow of the early diastolic movement of the tricuspid valve lateral segment, based on the data of the pulse-wave tissue Doppler.

\section{Invasive atrial pressure measurement}

Mean pressure in both atria was measured intraoperatively by the direct method in patients with paroxysmal AF prior to the radiofrequency $\mathrm{PVI}$.

\section{Statistical analysis}

The use of chi-squared test showed that the available sample complied with the normal distribution. Statistical analysis of our research results was carried out via the Student's t-test for a small sample. Statistically significant differences were considered at $p$ $<0.05$. The data are presented in the form of $M \pm m$, where $M$ is the mean of measured values, and $m$ is the error of the mean. To determine the relationship between the indicators, the linear Pearson-Spearman correlation coefficient was calculated. Using ROC analysis, the reliability of the model of ultrasound diagnostics of PVH was verified by the maximum and minimum RSPV diameters. ROC curves were built using the IBM SPSS software. To 
assess the quality of this model, we used the area under the ROC curve (AUC). The sensitivity and specificity of the ultrasound method for diagnosing the PVH were evaluated via the maximum and minimum diameters of RSVP [18].

\section{Results}

We examined 28 patients (12 men and 16 women) with paroxysmal $\mathrm{AF}$, who were scheduled for the radiofrequency PVI. Commonly, AF progressed in patients with coronary artery disease (64\%) and with essential hypertension (61\%).
CHF of FC I-III sensu the NYHA classification was diagnosed in 19 patients; specifically, 2 patients had FCI, 12 patients had FC II, and 5 patients had FC III.

In Group 1, the duration of AF and arterial hypertension was $7.00 \pm 2.28$ years and $20.75 \pm 4.88$ years, respectively. Besides the primary therapy, 9 patients were taking diuretic medicines: mineralocorticoid receptor antagonists (MCRA) and indapamide. In 4 patients, torasemide at a dose of $2.5-5 \mathrm{mg}$ was prescribed. Table 1 characterizes the patients in full.

Table 1. Characteristics of study subjects

\begin{tabular}{|c|c|c|c|}
\hline Parameters & Patients with AF and CHF ( $n=19)$ & Patients with AF and without $\mathrm{CHF}(n=9)$ & Control values $(n=44)$ \\
\hline Gender (male) & $6(31.6 \%)$ & $6(66.7 \%)^{\wedge}$ & $26(38.6 \%)$ \\
\hline Age (years) & $61.72 \pm 3.66^{\wedge}$ & $55.83 \pm 6.62^{\wedge}$ & $35.02 \pm 2.44$ \\
\hline Coronary artery disease: effort of physical exertion & $15(78.9 \%) *$ & $3(33.3 \%)$ & \\
\hline Arterial hypertension & $14(73.7 \%)$ & $8(88.9 \%)$ & \\
\hline Postmyocardial infarction cardiosclerosis & 0 & $1(11.1 \%)$ & \\
\hline Acute stroke in the past & $3(15.8 \%)$ & 0 & \\
\hline Dilated cardiomyopathy & $2(10.5 \%)$ & 0 & \\
\hline Type 2 diabetes & $2(10.5 \%)$ & $1(11.1 \%)$ & \\
\hline Paroxysmal AF & $19(100 \%)$ & $9(100 \%)$ & \\
\hline Duration of AF, years & $7.00 \pm 2.28 *$ & $3.60 \pm 1.80$ & \\
\hline Duration of hypertension, years & $20.75 \pm 4.88 *$ & $9.43 \pm 3.98$ & \\
\hline \multicolumn{4}{|l|}{$\mathrm{CHF}(\mathrm{FC})$} \\
\hline $\mathrm{FCl}$ & $2(10.5 \%)$ & 0 & \\
\hline FC II & $12(63.2 \%) *$ & 0 & \\
\hline FC III & $5(26.3 \%) *$ & 0 & \\
\hline Obesity & $8(42.1 \%)$ & $4(44.4 \%)$ & \\
\hline Therapy: beta blockers & $7(36.8 \%)$ & $2(22.2 \%)$ & \\
\hline ACEI/ARB & $10(52.6 \%) * / 9(47.4 \%) *$ & $1(11.1 \%) / 0$ & \\
\hline MCRA/ & $4(21.0 \%) /$ & $0 /$ & \\
\hline Indapamide and hydrochlorothiazide/ & $5(26.3 \%) * /$ & $0 /$ & \\
\hline Torasemide & $4(21.0 \%)$ & 0 & \\
\hline Calcium antagonists & $3(15.8 \%)$ & 0 & \\
\hline Statins & $11(57.9 \%)$ & $3(33.3 \%)$ & \\
\hline Antiarrhythmic therapy & $13(68.4 \%)$ & 3 (33.3\%) & \\
\hline
\end{tabular}

$\mathrm{AF}$, atrial fibrillation, $\mathrm{CHF}$, chronic heart failure, $\mathrm{FC}$, functional class, $\mathrm{ACEI} / \mathrm{ARB}$, angiotensin converting enzyme inhibitors/angiotensin receptor blockers. MCRA, mineralocorticoid receptor antagonists. * $p<0.05$ for patient groups compared with each other; ${ }^{\wedge} p<0.05$ for patient groups vs. control values.

Table 2. Echocardiographic and invasive parameters of hemodynamics

\begin{tabular}{|c|c|c|c|c|c|c|}
\hline Parameters & Control values $(n=44)$ & Patients with AF and CHF ( $n=19)$ & $P$ & Patients with AF and without $C H F(n=9)$ & $P$ & $P^{\prime}$ \\
\hline$\overline{\mathrm{LAVI}, \mathrm{mL}}$ & $49.29 \pm 4.33$ & $50.25 \pm 7.65$ & $<0.001$ & $40.26 \pm 3.17$ & $<0.001$ & 0.801 \\
\hline Simpson's ejection fraction, \% & $62.89 \pm 1.47$ & $58.63 \pm 6.79$ & 0.750 & $65.5 \pm 2.66$ & 0.808 & 0.176 \\
\hline Transmitral E/A & $1.61 \pm 0.07$ & $0.77 \pm 0.05$ & $<0.001$ & $0.75 \pm 0.08$ & $<0.001$ & 0.672 \\
\hline Septal e' & $13.25 \pm 0.63$ & $7.03 \pm 0.74$ & $<0.001$ & $6.88 \pm 0.79$ & $<0.001$ & 0.847 \\
\hline LV lateral e' & $17.85 \pm 0.94$ & $10.03 \pm 0.87$ & $<0.001$ & $10.62 \pm 1.94$ & $<0.001$ & 0.486 \\
\hline Mean E/e' & $6.83 \pm 0.29$ & $8.92 \pm 0.73$ & $<0.001$ & $8.62 \pm 1.31$ & $<0.001$ & 0.650 \\
\hline Calculated PCWP, mm Hg & $1.97 \pm 0.004$ & $11.48 \pm 1.04$ & $<0.001$ & $10.82 \pm 1.64$ & $<0.001$ & 0.491 \\
\hline Maximum pulmonary vein diameter, $\mathrm{mm}$ & $13.50 \pm 0.44$ & $22.39 \pm 0.95$ & $<0.001$ & $21.44 \pm 1.67$ & $<0.001$ & 0.246 \\
\hline Minimum pulmonary vein diameter, mm & $6.42 \pm 0.17$ & $11.78 \pm 1.19$ & $<0.001$ & $11.33 \pm 1.29$ & $<0.001$ & 0.902 \\
\hline Invasively measured LA pressure, mm Hg & 2-12 (7.9) [19] & $14.68 \pm 1.40$ & & $15.00 \pm 2.63$ & & 0.850 \\
\hline PASP, mm Hg & $15.23 \pm 1.24$ & $36.11 \pm 4.64$ & $<0.001$ & $29.33 \pm 3.28$ & $<0.001$ & 0.180 \\
\hline Transtricuspid E/A & $1.58 \pm 0.07$ & $0.82 \pm 0.04$ & $<0.001$ & $0.91 \pm 0.12$ & $<0.001$ & 0.064 \\
\hline RV lateral e' & $15.00 \pm 0.82$ & $8.73 \pm 0.83$ & $<0.001$ & $8.30 \pm 1.12$ & $<0.001$ & 0.466 \\
\hline $\mathrm{IVC}, \mathrm{cm}$ & $17.60 \pm 0.76$ & $22.41 \pm 1.35$ & $<0.001$ & $21.89 \pm 2.40$ & $<0.001$ & 0.651 \\
\hline Calculated RAP, mm Hg & $3.68 \pm 0.24$ & $10.36 \pm 0.81$ & $<0.001$ & $11.57 \pm 2.55$ & $<0.001$ & 0.251 \\
\hline Invasively measured RA pressure, $\mathrm{mm} \mathrm{Hg}$ & $1-7(3.9)[19]$ & $6.75 \pm 0.63$ & & $6.13 \pm 1.13$ & & 0.288 \\
\hline
\end{tabular}

$A F$, atrial fibrillation, $C H F$, chronic heart failure; $L A V I$, left atrial volume index; $E / A$, the ratio of peak velocity blood flow from left ventricular relaxation in early diastole (the $\mathrm{E}$ wave) to peak velocity flow in late diastole caused by atrial contraction (the A wave); LV, left ventricle; Mean E/e', the ratio of early diastolic blood flow velocity to the velocity of the lateral and medial parts of the mitral valve annulus; PCWP, pulmonary capillary wedge pressure; LA, left atrium; PASP, pulmonary artery systolic pressure; RV, right ventricle; IVC, inferior vena cava; RAP is the right atrial pressure; RA, right atrium. P denotes statistical significance of differences between each group of patients and the control group. $\mathrm{P}^{\prime}$ denotes statistical significance of differences between groups of patients. 
Table 3. Correlation of invasively measured left atrial pressure with echocardiographic parameters

\begin{tabular}{|c|c|c|}
\hline Parameters & Invasively measured pressure in the $\mathrm{LA}, \mathrm{mm} \mathrm{Hg}$ & Invasively measured pressure in the $\mathrm{RA}, \mathrm{mm} \mathrm{Hg}$ \\
\hline LA volume, $\mathrm{mL}$ & -0.12 & \\
\hline Mean E/e' & -0.29 & \\
\hline Calculated PCWP, mm Hg & -0.11 & \\
\hline Maximum pulmonary vein diameter, $\mathrm{mm}$ & -0.06 & \\
\hline Minimum pulmonary vein diameter, $\mathrm{mm}$ & $0.65^{*}$ & \\
\hline PASP, $\mathrm{mm} \mathrm{Hg}$ & 0.21 & 0.54 \\
\hline IVC, $\mathrm{cm}$ & & $0.49 *$ \\
\hline Calculated RAP, $\mathrm{mm} \mathrm{Hg}$ & & 0.16 \\
\hline
\end{tabular}

LA, left atrium; RA, right atrium; PCWP, pulmonary capillary wedge pressure; PASP, pulmonary artery systolic pressure; IVC, inferior vena cava; RAP, right atrial pressure. * Statistically significant correlation, $\mathrm{p}<0.05$.

In Group 2, the duration of AF and arterial hypertension was $3.60 \pm 1.80$ years and $9.43 \pm 3.98$ years, correspondingly. Patients in this group were receiving the basic therapy without diuretic medications.

Patients of the control group were significantly younger than in two experimental groups, because we were not able to find virtually healthy people at ages similar to the subjects in Groups 1 and 2.

Patients with $\mathrm{AF}$, and with or without $\mathrm{CHF}$, compared with the control subjects, based on echocardiography data, had left atrial (LA) dilatation confirmed by the LA volume index (LAVI) values of $67.70 \pm 1.91 \mathrm{~mL}, 68.00 \pm 3.17 \mathrm{~mL}$ and $49.29 \pm 4.33 \mathrm{~mL}$, respectively (Table 2); the maximum RSPV diameter of $22.39 \pm 0.95 \mathrm{~mm}$, $21.44 \pm 1.67 \mathrm{~mm}$ and $13.50 \pm 0.44 \mathrm{~mm}$, correspondingly (Figures $1 \mathrm{~A}$, $2 \mathrm{~A}, 3 \mathrm{~A})$; and the minimum RSPV diameter of $11.78 \pm 1.19 \mathrm{~mm}$, $11.33 \pm 1.29 \mathrm{~mm}$ and $6.42 \pm 0.17 \mathrm{~mm}$, respectively (Figures $1 \mathrm{~B}, 2 \mathrm{~B}$, $3 B$ ). As for the mean $E / e^{\prime}$, it was very similar in both experimental groups: $8.92 \pm 0.73$ vs. $8.62 \pm 1.31$. This finding implied that values of the mean $\mathrm{E} / \mathrm{e}^{\prime}$ were, so to speak, in the grey zone and required additional investigation in order to clarify the presence or absence of hypertension in the LA [10]. For the patients with AF, and with or without CHF, the calculated PCWP was significantly higher than in the control group, but still under 12 - i.e., it was within the range of reference values [19].

Hence, sensu the existing ultrasound methods for detecting the congestion in the pulmonary circulation, patients with paroxysmal AF, regardless of CHF diagnosed by cardiologists, had no PVH. However, the invasively measured pressure in LA was elevated both in the group of patients with $\mathrm{AF}$ and $\mathrm{CHF}$ $(14.68 \pm 1.40 \mathrm{~mm} \mathrm{Hg})$ and in the group with AF but without CHF $(15.00 \pm 2.63 \mathrm{~mm} \mathrm{Hg})$. This finding implied the presence of the PVH and $\mathrm{CHF}$ in patients of both groups.

We established the positive correlation between the minimum diameter of RSPV and invasive mean pressure in the LA ( $r=0.65$, $p<0.05$ ). We did not find statistically significant correlation between the maximum RSPV diameter and invasive mean pressure in the LA ( $r=-0.06)$. Likewise, there was not significant correlation between the mean $\mathrm{E} / \mathrm{e}^{\prime}$ and invasive mean pressure in the LA ( $r=-$ 0.29) (Table 3).

We performed the ROC analysis to verify the reliability of the ultrasound diagnostic model for PVH based on the maximum and minimum RSPV diameters. For the maximum pulmonary vein (PV) diameter, $A \cup C=0.599 \quad(p<0.05)$, which indicated that this model had an average quality level. The equilibrium point was the value of the maximum RSPV diameter of $21.7 \mathrm{~mm}$, which corresponded to the norm (sensitivity of $75 \%$, specificity of $86 \%$ ).

For the minimum diameter of the PV, AUC $=0.613(p<0.05)$, which implied that this model had an average quality level as well.
The equilibrium point was the minimum diameter of RSPV of 10.5 $\mathrm{mm}$, which corresponded to the norm (sensitivity of $85 \%$, specificity of $86 \%)$.

Accordingly, the method for determining PVH via measuring the maximum and/or minimum diameters of the PV could be effectively used as noninvasive diagnostics of the venous congestion in the pulmonary circulation.

For the patients with $\mathrm{AF}$ and with or without $\mathrm{CHF}$, the calculated pressure in the RA was $10.36 \pm 0.81$ and $11.57 \pm 2.55(\mathrm{mmHg})$, respectively; the invasive measurement method yielded the values of $6.75 \pm 0.63$ and $6.13 \pm 1.13(\mathrm{mmHg})$, respectively. This finding implied that the pressure calculated via echocardiography was overestimated.

There was a positive correlation between invasively measured mean pressure in the RA and IVC diameter on expiration ( $r=0.49$, $p<0.05)$. For the maximum IVC diameter, the ROC curve plot was obtained with AUC=0.832 ( $p<0.05)$, which indicated that this model had a very good quality level. The equilibrium point was the value of the IVC diameter of $18.5 \mathrm{~mm}$, which corresponded to the norm (sensitivity of $100 \%$, specificity of $92 \%$ ).

\section{Discussion}

It is known, that in arrhythmogenesis of the AF, PVs play an essential role as a trigger or driver of $\operatorname{AF}[20,21]$. Prior studies using cardiac imaging modalities demonstrated that AF patients had significantly enlarged PVs, compared with the control [22]. This finding suggests that structural alteration of PVs is related to the AF development. Our study demonstrated that patients with paroxysmal $\mathrm{AF}$, and with or without $\mathrm{CHF}$, compared with the control group, according to echocardiography, exhibited the dilatation of both maximum and minimum RSPV diameters. There was a positive correlation between the minimum RSPV diameter and invasive mean pressure in the $L A(R=0.65, P<0.05)$. Our study revealed that asymptomatic patients with $A F$ had an augmented invasively measured pressure in LA and structural changes in LA and PVs that did not differ from those of the patients with simultaneous presence of $\mathrm{AF}$ and CHF. This finding suggests that in $\mathrm{CHF}$ diagnostics, it is preferable to rely on changes in the structure and function of the heart, detected by the echocardiography, rather than on symptoms and manifestations alone.

In this study, the sensitivity and specificity of ultrasound methods of congestion diagnostics in the pulmonary and systemic circulatory systems were determined in comparison with the gold standard - i.e., the invasive pressure measurement in the LA and RA of the heart. 


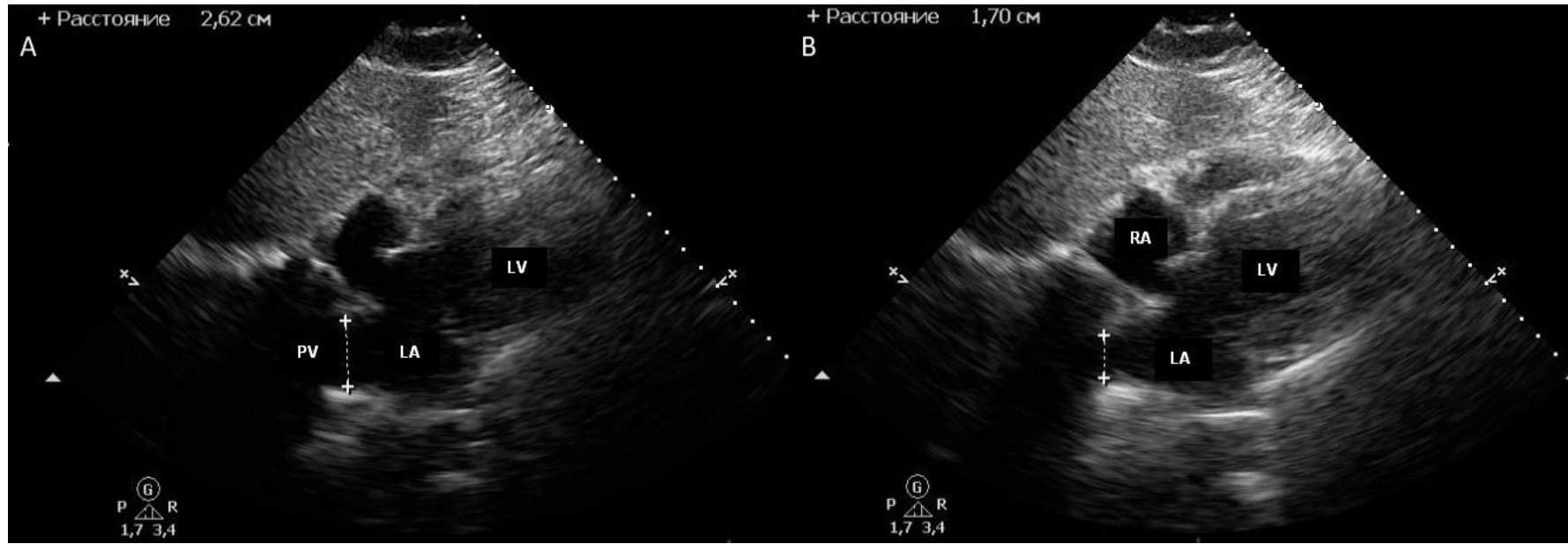

Figure 1. Maximum (A) and minimum (B) diameter of RSPV in patients with AF and CHF. The maximum diameter of RSPV was $26.2 \mathrm{~mm}$; the minimum diameter of RSPV was $17.0 \mathrm{~mm}$.

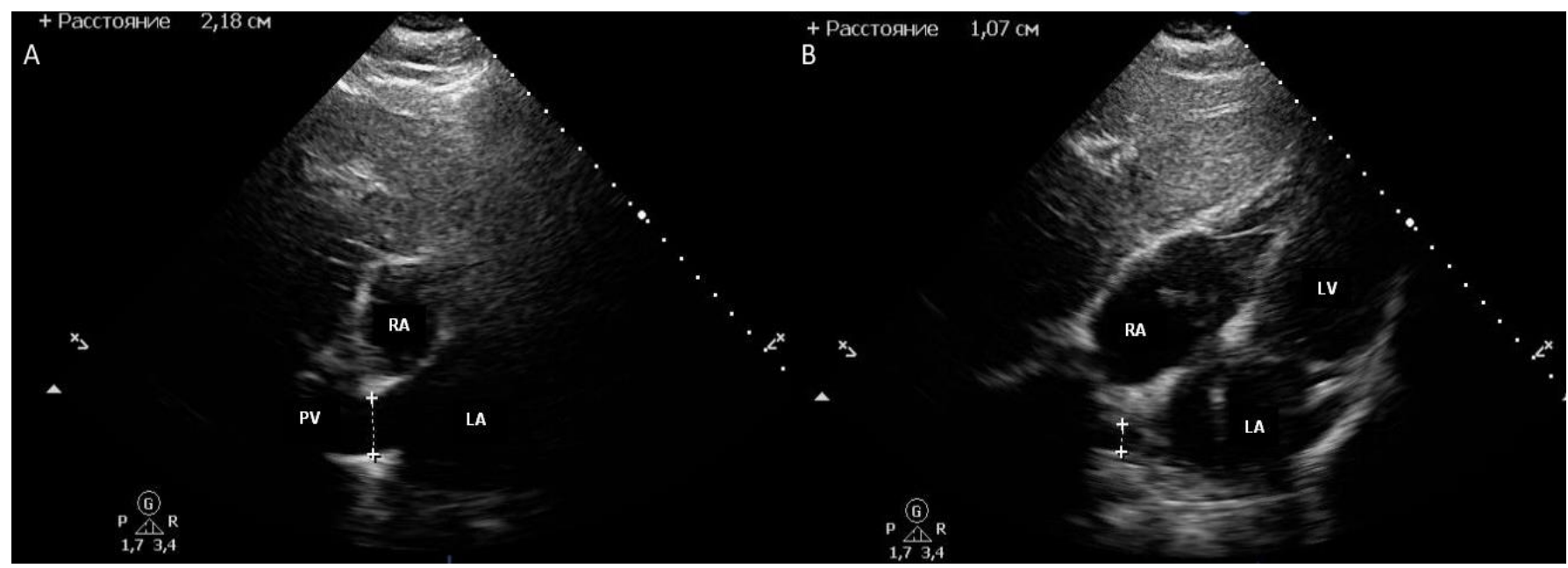

Figure 2. Maximum (A) and minimum (B) diameter of RSPV in patients with AF and without CHF. The maximum diameter of RSPV was 21.8 $\mathrm{mm}$; the minimum diameter of RSPV was $10.7 \mathrm{~mm}$.

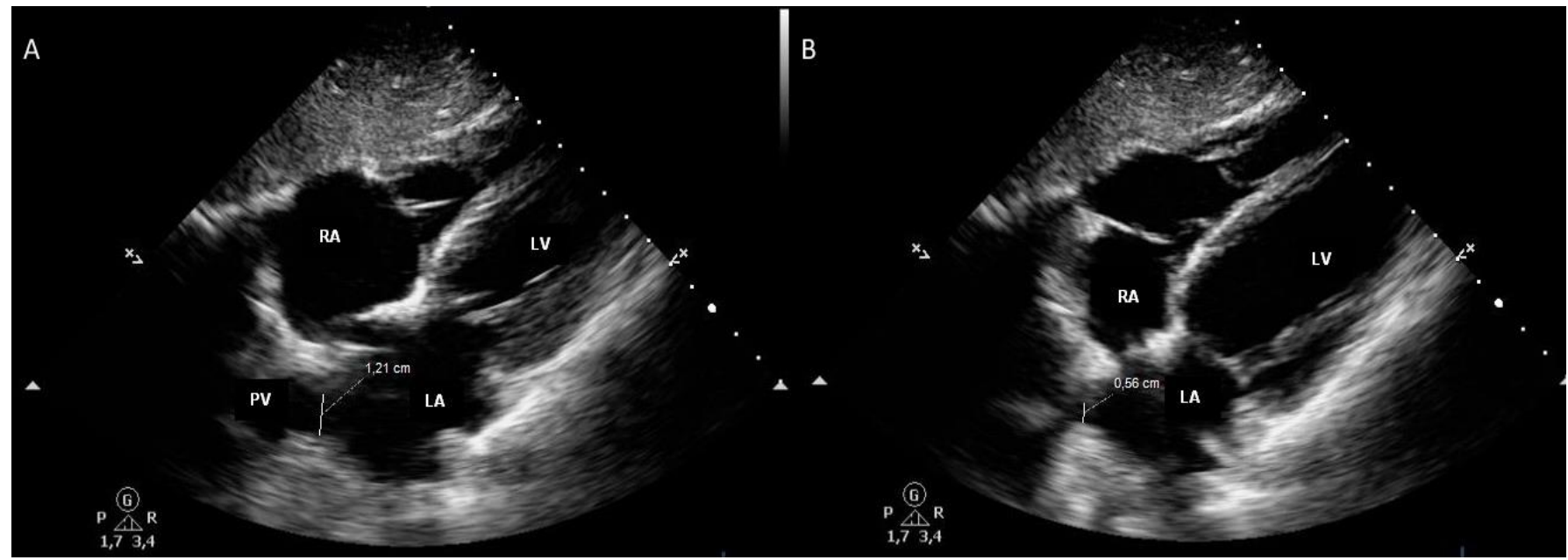

Figure 3. Maximum (A) and minimum (B) diameter of RSPV: control values. The maximum diameter of RSPV was $12.1 \mathrm{~mm}$; the minimum diameter of RSPV was $5.6 \mathrm{~mm}$ 
The method of noninvasive diagnostics of PVH is based on measuring the maximum diameter of any of the visible pulmonary veins pushing blood into the LA during diastole, and the minimum diameter during atrial systole. If the maximum diameter of any visible pulmonary vein is greater than $18 \mathrm{~mm}$, and its minimum diameter is greater than $9 \mathrm{~mm}$, then the venous congestion in the pulmonary circulation is diagnosed [14]. The sensitivity of the method for the maximum RSPV diameter greater than $21.7 \mathrm{~mm}$, as an ultrasound criterion for $\mathrm{PVH}$, was $75 \%$, and its specificity was $86 \%$. The sensitivity of the method for the minimum diameter of the RSPV greater than 10.5, as an ultrasound criterion for PVH, was $85 \%$, and its specificity constituted $86 \%$.

In this study, in 24 of 28 patients with $A F$, the pressure in LA $\left(14.79 \pm 1.18 \mathrm{~mm} \mathrm{Hg}\right.$ ) was elevated, whereas mean $\mathrm{E} / \mathrm{e}^{\prime}$ values in patients with $\mathrm{AF}$, and with or without $\mathrm{CHF}$, were $8.92 \pm 0.73$ and $8.62 \pm 1.31$, respectively, which implied the gray zone of values, requiring additional examination methods to determine the pressure in the LA [10]. We did not find significant correlation between the mean $E / e^{\prime}$ and invasive mean pressure in the LA $(r=-0.29)$. A systematic review of nine studies has reported only modest correlations of $\mathrm{E} / \mathrm{e}^{\prime}$ with invasive filling pressures in $\mathrm{CHF}$ patients with preserved ejection fraction, because some of these studies did not reveal correlations similar to ours [23].

It is well-known that the presence of congestion in the pulmonary circulation and the necessity to take diuretics in addition to primary therapy prevents the development of CHF decompensation [10]. In this study, in addition to the primary therapy, 9 patients were prescribed diuretic medicines: MCRA and indapamide. In 4 patients, torasemide at a dose of 2.5-5 mg was prescribed. At the same time, PVH was detected in 24 patients via using invasive and newly proposed ultrasound technique of measuring the maximum and/or minimum diameter of the PV. Fluid retention in the body with CHF may lead to the development of atrial myocardial edema [24]. However, an appointment of adequate diuretic therapy in patients with simultaneously present paroxysmal $\mathrm{AF}$ and $\mathrm{CHF}$ reduces the frequency of arrhythmia recurrence [25].

Previously known ultrasound methods for detecting congestion in the pulmonary circulation did not show signs of increased pressure in the LA. The calculated PAWP in patients with $\mathrm{AF}$, and with or without CHF, was not informative as well, considering that identified values were within the reference range - $11.48 \pm 1.04$ and $10.82 \pm 1.64(\mathrm{~mm} \mathrm{Hg})$, respectively. Hence, the diagnostics of $\mathrm{CHF}$ and congestion phenomena in pulmonary circulation and, consequently, inappropriate treatment was not unusual, including the lack of prescribing loop diuretics or their incorrect dosages.

It should be noted that the method of ultrasound diagnostics of PVH by examining the maximum and minimum PV diameters in patients with CHF has also allowed evaluating the effectiveness of the diuretic treatment. In patients with venous congestion in the pulmonary circulation, the maximum and minimum diameters of visualized PVs decreased in response to an adequate diuretic therapy [26].

Determining the congestion in systemic circulation does not usually cause difficulties for clinicians, because contrary to congestion in pulmonary circulation, the clinician can objectively assess the presence of edema and increase in the liver size by percussion and palpation. However, it is imperative to differentiate between the edema of the lower limbs that occurs in varicose veins, lymphostasis, and an increase in the liver size caused by liver diseases, including steatohepatitis, which has become widespread in recent years.

Our study determined the sensitivity and specificity of the proposed ultrasound method for congestion diagnostics in systemic circulation via the diameter of IVC on expiration and via the gold standard of invasive measurement of pressure in RA. The sensitivity of the IVC diameter exceeding $18.5 \mathrm{~mm}$ on expiration was $100 \%$, and the specificity was $92 \%$. We established positive correlations between invasively measured mean pressure in the RA and systolic pressure in the pulmonary artery $(r=0.54$, $p<0.05)$, and maximum diameter of IVC as well $(r=0.49, p<0.05)$

\section{Limitations}

Our sample size was rather small. The studied patients did not have wide range of atrial pressure values. Consequently, actual the relationship between the maximum and/or minimum PV diameter and blood pressure in the LA could have been underestimated. Hence, further research is needed on a large sample of patients.

\section{Conclusion}

The proposed ultrasound method for diagnosing congestion in the pulmonary circulation via maximum and/or minimum RSPV diameter in the same way as the conventional technique of detecting the congestion in systemic circulation via IVC diameter in patients with AF and CHF can be effectively employed in clinical practice, providing an adequate diuretic therapy and significantly reducing the number of $\mathrm{CHF}$ decompensation cases.

\section{Funding}

This study was partially funded by the Public Procurement of the Ministry of Healthcare of the Russian Federation for 2021-2023 to Ural State Medical University, No. 121030900298-9, "Individualization of Selecting Comprehensive Geroprophylaxis".

\section{Conflict of Interest}

The authors declare that they have no conflicts of interest.

\section{References}

1. Dharmarajan K, Hsieh AF, Lin Z, Bueno H, Ross JS, Horwitz LI, et al Diagnoses and timing of 30-day readmissions after hospitalization for heart failure, acute myocardial infarction, or pneumonia. JAMA 2013 309(4): 355-363. https://doi.org/10.1001/jama.2012.216476.

2. SOLVD Investigators, Yusuf S, Pitt B, Davis CE, Hood WB Jr, Cohn JN. Effect of enalapril on mortality and the development of heart failure in asymptomatic patients with reduced left ventricular ejection fraction. $N$ Engl J Med 1992; 327(10): 685- 691. https://doi.org/10.1056/nejm199209033271003.

3. Cleland JG, Swedberg K, Follath F, Komajda M, Cohen-Solal A, Aguilar $\mathrm{JC}$, et al. The EuroHeart Failure survey programme - a survey on the quality of care among patients with heart failure in Europe. Part I: Patient characteristics and diagnosis. Eur Heart J 2003; 24(5): 442-463. https://doi.org/10.1016/s0195-668x(02)00823-0.

4. Maggioni AP, Dahlström U, Filippatos G, Chioncel O, Leiro MC, Drozdz J, et al. EURObservational Research Programme: The heart failure pilot survey (ESC-HF Pilot). Eur J Heart Fail 2010; 12(10): 1076-1084. https://doi.org/10.1093/eurihf/hfq154

5. Wang TJ, Larson MG, Levy D, Vasan RS, Leip EP, Wolf PA, et al Temporal relations of atrial fibrillation and congestive heart failure and their joint influence on mortality: The Framingham Heart Study. 


\section{Circulation \\ 2003; \\ 107(23): \\ $2920-2925$}

https://doi.org/10.1161/01.cir.0000072767.89944.6e.

6. Sato N, Kajimoto K, Asai K, Mizuno M, Minami Y, Nagashima M, et al. Acute decompensated heart failure syndromes (ATTEND) registry. $A$ prospective observational multicenter cohort study: Rationale, design, and preliminary data. Am Heart J 2010; 159(6): 949-955.e1. https://doi.org/10.1016/j.ahj.2010.03.019.

7. Abraham WT, Fonarow GC, Albert NM, Stough WG, Gheorghiade M, Greenberg $\mathrm{BH}$, et al. Predictors of in-hospital mortality in patients hospitalized for heart failure: insights from the Organized Program to Initiate Lifesaving Treatment in Hospitalized Patients with Heart Failure (OPTIMIZE-HF). J Am Coll Cardiol 2008; 52(5): 347-356. https://doi.org/10.1016/j.jacc.2008.04.028.

8. Fomin IV. Chronic heart failure in Russian Federation: What do we know and what to do? Russian Journal of Cardiology 2016; (8): 7-13. Russian. https://doi.org/10.15829/1560-4071-2016-8-7-13.

9. Mareev VYu, Fomin IV, Ageev FT, Arutyunov GP, Begrambekova YuL, Belenkov YuN, et al. Chronic heart failure (CHF). Russian Heart Failure Journal 2017;18(1(100)): 3-40. Russian. https://doi.org/10.18087/rhfj.2017.1.2346.

10. Ponikowski P, Voors AA, Anker SD, Bueno H, Cleland JG, Coats AJ, et al. 2016 ESC Guidelines for the diagnosis and treatment of acute and chronic heart failure: The Task Force for the diagnosis and treatment of acute and chronic heart failure of the European Society of Cardiology (ESC) developed with the special contribution of the Heart Failure Association (HFA) of the ESC. Eur Heart J 2016; 37(27): 21292200. https://doi.org/10.1093/eurhearti/ehw128.

11. Mullens W, Damman K, Harjola VP, Mebazaa A, Brunner-La Rocca HP, Martens $P$, et al. The use of diuretics in heart failure with congestion A position statement from the Heart Failure Association of the European Society of Cardiology. Eur J Heart Fail 2019; 21(2): 137-155. https://doi.org/10.1002/ejhf.1369.

12. Ommen SR, Nishimura RA, Appleton CP, Miller FA, Oh JK, Redfield $M M$, et al. Clinical utility of Doppler echocardiography and tissue Doppler imaging in the estimation of left ventricular filling pressures. A comparative simultaneous Doppler-catheterization study. Circulation 2000; 102(15): 1788-1794. https://doi.org/10.1161/01.cir.102.15.1788.

13. Ciozda W, Kedan I, Kehl DW, Zimmer R, Khandwalla R, Kimchi A. The efficacy of sonographic measurement of inferior vena cava diameter as an estimate of central venous pressure. Cardiovasc Ultrasound 2016; 14(1): 33. https://doi.org/10.1186/s12947-016-0076-1.

14. Kirillova VV. Method for ultrasonic early diagnosis of venous pulmonary hypertension for patients with chronic heart failure. The RF Patent for Invention. No. RU 2634633 C. 2017. Russian. https://elibrary.ru/item.asp?id=38288812.

15. Kirillova VV. Early ultrasound diagnostics of pulmonary venous hypertension. Eur J Heart Failure 2017;19 (Suppl 1): 496. https://doi.org/10.1002/ejhf.833.

16. Nagueh SF, Middleton KJ, Kopelen HA, Zoghbi WA, Quiñones MA. Doppler tissue imaging: A noninvasive technique for evaluation of left ventricular relaxation and estimation of filling pressures. J Am Coll Cardiol 1997; 30(6): 1527-1533. https://doi.org/10.1016/s07351097(97)00344-6.

17. Nagueh MF, Kopelen HA, Zoghbi WA, Quiñones MA, Nagueh SF. Estimation of mean right atrial pressure using tissue Doppler imaging. Am J Cardiol 1999; 84(12): 1448-1451. https://doi.org/10.1016/s00029149(99)00595-0.

18. Grigoryev SG, Lobzin YuV, Skripchenko NV. The role and place of logistic regression and ROC analysis in solving medical diagnosing task. Journal Infectiology 2016: 8(4); 36-45. Russian. https://doi.org/10.22625/2072-6732-2016-8-4-36-45.

19. Braunwald E, Brockenbrough EC, Frahm CJ, Ross J Jr. Left atrial and left ventricular pressures in subjects without cardiovascular disease: observations in eighteen patients studied by transseptal left heart catheterization. Circulation 1961; 24: 267-269. https://doi.org/10.1161/01.cir.24.2.267.

20. Haïssaguerre $M$, Jaïs $P$, Shah DC, Takahashi A, Hocini M, Quiniou G, et al. Spontaneous initiation of atrial fibrillation by ectopic beats originating in the pulmonary veins. N Engl J Med 1998; 339(10): 659666. https://doi.org/10.1056/nejm199809033391003.

21. Haïssaguerre $M$, Sanders $P$, Hocini $M$, Jaïs $P$, Clémenty J. Pulmonary veins in the substrate for atrial fibrillation: the "venous wave" hypothesis. J Am Coll Cardiol 2004; 43(12): 2290-2292. https://doi.org/10.1016/j.jacc.2004.03.036

22. Tsao HM, Yu WC, Cheng HC, Wu MH, Tai CT, Lin WS, et al. Pulmonary vein dilation in patients with atrial fibrillation: Detection by magnetic resonance imaging. J Cardiovasc Electrophysiol 2001; 12(7): 809-813. https://doi.org/10.1046/j.1540-8167.2001.00809.x.

23. Nauta JF, Hummel YM, van der Meer P, Lam CSP, Voors AA, van Melle JP. Correlation with invasive left ventricular filling pressures and prognostic relevance of the echocardiographic diastolic parameters used in the 2016 ESC heart failure guidelines and in the 2016 ASE/EACVI recommendations: A systematic review in patients with heart failure with preserved ejection fraction. Eur J Heart Fail 2018, 20(9): 1303-1311. https://doi.org/10.1002/ejhf.1220.

24. Kirillova VV. Myocardial remodeling in patients with atrial fibrillation with chronic heart failure. Translational Medicine 2018; 5(2): 15-21. Russian. https://doi.org/10.18705/2311-4495-2018-5-2-15-21.

25. Kirillova VV. Method of treating paroxysmal form of atrial fibrillation in patients with chronic heart failure in arterial hypertension. The RF Patent for Invention. No. RU 2703517 C1. 2019. Russian. https://elibrary.ru/item.asp?id=41185135.

26. Kirillova VV. Ultrasound criteria of the diuretic therapy effectiveness in chronic heart failure. The Siberian Journal of Clinical and Experimental Medicine 2018; 33(2): 51-55. Russian. https://doi.org/10.29001/2073-8552-2018-33-2-51-55.

\section{Authors:}

Venera V. Kirillova - MD, PhD, Senior Lecturer, Department of Biochemistry, Ural State Medical University, Ekaterinburg, Russia; Senior Researcher, Laboratory of Anti-Aging Technology, Institute for Medical Cell Technology, Ekaterinburg, Russia; cardiologist, echocardiographer, Uralskaya Clinic LLC, Ekaterinburg, Russia. https://orcid.org/0000-00016254-0756.

Andrey V. Smorgon - MD, Researcher, Department of Ultrasound and Functional Diagnostics, Research Institute of Cardiology, Tomsk National Medical Research Center, Tomsk, Russia.

Alla A. Garganeeva - MD, DSc, Professor, Head of the Department of Myocardial Pathology, Research Institute of Cardiology, Tomsk National Medical Research Center, Tomsk, Russia. https://orcid.org/0000-00029488-6900.

Roman E. Batalov - MD, PhD, Lead Researcher, Department of Heart Arrhythmias, Research Institute of Cardiology, Tomsk National Medical Research Center, Tomsk, Russia. https://orcid.org/0000-0003-1415-3932. Viktor N. Meshchaninov - MD, DSc, Professor, Heard of Laboratory of Anti-Aging Technology, Institute for Medical Cell Technology, Ekaterinburg, Russia. https://orcid.org/0000-0001-7928-2503.

Lyudmila A. Sokolova - MD, DSc, Professor, Department of Hospital Therapy and Emergency Medicine, Ural State Medical University, Ekaterinburg, Russia. https://orcid.org/0000-0002-5931-9417.

Maria S. Blagodareva - MD, Instructor Department of Biochemistry, Ural State Medical University, Ekaterinburg, Russia; Junior Researcher, Laboratory of Anti-Aging Technology, Institute for Medical Cell Technology, Ekaterinburg, Russia. https://orcid.org/0000-0003-0640-210X.

Mikhail S. Khlynin - MD, PhD, Researcher, Department of Heart Arrhythmias, Research Institute of Cardiology, Tomsk National Medical Research Center, Tomsk, Russia. https://orcid.org/0000-0002-9885-5204.

Sergey V. Popov - MD, DSc, Associate Professor, Director of Research Institute of Cardiology, Tomsk National Medical Research Center, Tomsk, Russia. https://orcid.org/0000-0002-9050-4493. 